\title{
On The Economics of Environmental Restrictions at Hydropower Plants: Optimize the Costs
}

\author{
Hasan Huseyin Coban, \\ Ardahan University, Engineering Faculty, Department of Electrical Engineering, \\ 75000, Ardahan, Turkey. \\ E-mail: huseyincoban@ardahan.edu.tr,
}

\begin{abstract}
This paper examines a stochastic approach to solving the impact of water usage rate restrictions imposed on hydro operations in order to maximize income. The hydroelectric power plant was evaluated within a stochastic control framework by taking into account operational constraints such as cash flows, water use and minimum flow rate restrictions for environmental protection. The Quasi-Newton Method of the income maximizing working mode decisions of a hydropower plant is determined for various constraints on the value of useable water. A Turkish hydropower is used for the case study; on Kura River in Ardahan city. The income is negatively affected, although not very large, for a range of restrictions the impact is not large. Numerical results point out that not to take into account environmental constraints may noticeably increase the cash-flows value of hydropower plant.
\end{abstract}

Keywords: environmental restrictions, hydroelectrical energy, hydropower plant, stochastic optimization, ramping rate.

DOI: $10.7176 / \mathrm{JSTR} / 5-7-10$

\section{Introduction}

Hydropower is a renewable, clean and environmentally friendly energy source. It produces $3975 \mathrm{TWh}$, and it supplies $71 \%$ of all renewable electricity [1]. To achieve the target 1064 GWh of installed power capacity in 2016, $16.4 \%$ of the world's electricity produced from all sources [2]. Generally, hydropower is a very important energy supply option for various reasons. If we list these reasons briefly; first, for a power source that is clean and renewable that can provide to sustainable advancement because it doesn't pollute the air because no fuels are burned and it uses the Earth's water cycle to generate electricity, typically low-cost power. Second, it energy supplies by reducing the dependence on importedfuel supplies that carry the risks of price volatility, supply uncertainty, and foreign currency demands. Third, hydro facilities can propose various co-benefits such as reservoir for drinking water and irrigation, flood risk protection, growing plants in water opportunities. Lastly, hydropower plants contribute more renewables especially with solar and wind farms; to be added to the system by providing rapid-response power during periods of low electricity demand can be used to run intermittent loads, as in the case of pumped hydro energy storage; when wind and solar power facilities are generating excess power the role of these sources are mainly to save water $[3,4]$.

In order to produce countries', own energy without being reliant on foreign energy sources; a large number of regulations and economic incentives exist worldwide and in Turkey as well; to develop more environmentally, friendly, cheap power generation technologies. Notwithstanding, when applying such procedure some difficulties normally occur: (i) what technologies should be considered environmentally friendly; and (ii) how does one find a suitable harmony between the benefits of electricity generation and the costs of environmental limitations? This paper examines and finds a solution from an economic point of the view to the question of whether environmental restrictions on hydroelectric dams are acceptable. In recent years authors have shown an increased interest and published articles $[5,6,7,8,9,10,11,12,13,14]$ in the economics literature. Just as these researches; the solutions to the above difficulties in applying optimization for economic valuation to the specific environmental impacts that can be characterized.

90 | P a g e

www.iiste.org 
A remarkable result is that the total amount of generated electricity may be increased or decreased by limitations of the value water usage which affects the income over a time horizon [5]. An operator of the facility's effort influences the profit in the face of restrictions. In response to the limitations of the reservoir water level, operators maintain the production of energy in so far as possible during peak periods. If increased energy production from the hydroelectric power plant requires the reduction of the power generated by fossil fuel-fired plants, this can provide no additional benefit to the water ecosystem downstream the hydroelectric power plant, as well as an additional environmental gain for water use limitations.

When optimizing hydroelectric power plants operation, all environmental and technological constraints must be taken into consideration [6]. The ecological limitations [7] which have on the potential income are considered as a permanent parameter set. In order to potentially review these limitations, the cost of restrictions and their impact on income will be studied.

In this paper, the effect of the environmental restriction ratio applied by a regulatory authority (DSIGeneral Directorate of state hydraulic works) on the economic operations of a power plant is investigated. Based on a small scale real-world facility in Turkey is modeled on a revenue maximization hydroelectric power plant.

It is considered that the facility collaborates with the spot market. It is explored with the optimal decisions of the operator regarding the hydro energy production in the short and medium term. The issue of the uncertainty of the price of electricity is abstracted and the uncertainty of water flow rate is known. The environmental constraints $[7,8]$ are considered as optimization variables. Multi-criteria optimization models are applied as a decision making problem of simultaneous optimization. The main contribution of the paper is to compare optimization results with help of Monte-Carlo method [9] and have acceptable final decisions.

A large literature examining the economics of electricity markets have relied. This paper provides a broad literature examining the costs of regulation in the electricity market environment.

The book [10] describes the views hydropower plants economically; the basic model for management of hydropower and describes how to operate the water reservoir and the facility.

The article [11] discusses how better decision-making, more discriminate site selection and more effective mitigation measures could significantly reduce the environmental impacts of hydropower. The goal of the study is to analyze social, economic and environmental costs and risks of hydroelectric dams, in Vietnam. The study discusses the main shortcomings to calculate, manage and reduce the environmental and social costs and risks of hydroelectric power.

The paper [12] focuses on the prediction of the short-term economic impact caused by environmental restrictions on hydroelectric operations. The paper describes an hourly framework for estimating the short-term economic costs of introducing a specific hourly restriction set for hydroelectric operations. The result of the approach was appropriate for the analysis of the impacts of a wide-range of hourly constraints. Within the described restrictions, the methodology has produced critical results in management the decision, together with research findings linking the impacts of dam operations with changes in the ecosystem in the downstream basin

The paper [13] shows regulations governing the allowed rate of discharges from hydroelectric dams and their impact on the total cost of producing electricity from both hydroelectric and fossil fuel sources. The results have critical implications for both water and electricity policy.

The paper [14] analyzes the impact on the economics of ramping rate limits which provide environmental benefits on hydro operations for the purpose of protecting aquatic ecosystems. By using for different types of constrains on water intake data for a representative hydrological process in Ontario (Canada), the decisions of a hydroelectric plant operator to maximize profits are solved by a dynamic optimization model. The paper tries to evaluate the short-term cost of maximum ramping rates on a hypothetical plant. It recommends the presence of ramp rates may increase the generation of electrical energy if there is no maximum value for the contract request.

This paper is organized as follows: in Section 2, the answer to the question "how was the project designed?" is explained. Findings from previous researches such as energy supply and demand analysis, assumptions and model formulation are presented. The relationship with other existing or planned projects that contributed to the conception of the paper is also presented. Description of the prototype hydro plant is specified in Section 3. The analysis of hydroelectric power plant operations and profit; and 
the effects of environmental changes on profit are taken into account in Chapter 3 as well. Lastly, Section 4 summarizes conclusions and offers some ideas for fruitful new directions of future research.

\section{Task Statement}

It is assumed that the owner of the power plant is striving to maximize income in market conditions subject to various restrictions which will be defined below chapter. Income maximization involves determining the hourly electricity price and the amount of energy generation which depends on a nonlinear function on the head pond and hourly discharged water through the turbine(s), as given in Equation (3).

The formulation of the optimization task involves the estimated in the space of income and the limitations parameters. The analysis considers three categories of limits of water usage and income related to the switch to hydropower plant: Firstly, a model developed to estimate the variables; namely electricity market price and water inflow data are performed thanks to an Artificial Neural Network (ANN). Reallife statistics and previous estimates of electricity prices and water inflows data are required to achieve future forecasting processes.

Secondly, short term (24-hours) optimization of the HPP working conditions. The input-output characteristics of the power plant are applied on non-linear programming and non-linear approximation model.

The definition of the methodology and the validation of the algorithm with the task formulation are presented in the previous articles [15,16] and in the thesis [9]. In this paper, the formulation of the optimization task estimated in two parameter areas, particularly, the limitations and the income.

The objective function of the power plant is to maximize its income in the electricity market environment. The optimal daily generation schedule is achieved by 24-hour optimization of the amount of generated electricity at each hour. The purpose of an investor can be presented as follows:

$$
\begin{aligned}
I & \rightarrow \max \\
I_{T}= & \sum_{k}^{K} P_{k} \cdot C_{k} \rightarrow \max \\
I_{T}= & \sum_{k}^{K} \sum_{l}^{L} n_{k} \cdot g \cdot q_{k} \cdot h_{l k} \sum_{t}^{T} c_{t} \\
& \forall t \in T, \forall k \in K, \forall l \in L
\end{aligned}
$$

Where

$I$ - expected income of the HPP in EURO.

$T$ - number of hours.

$K, l$ - the sets of the hourly recording periods of reservoir.

$g-$ acceleration due to gravity force $=9.81 \mathrm{~m} / \mathrm{s}^{2}$.

$n$-the efficiency of the HPP.

$h-$ net head; in meter. It is the vertical distance in water levels between the hydro intake and water release from the turbine where the hydro discharge point. The power production efficiency all comes down to the head and flow which is a non-linear function of the net head of the water discharging through the turbine and the flow rate in another word converting this water power into electricity [17]. The amount of power, and therefore generated energy is proportional to the head and the flow.

$c$ - electricity market price in EURO [18].

Subject to:

The reservoir storage volumes must be within the maximum and minimum reservoir storage volume.

92 I P a g e

www.iiste.org 


$$
\boldsymbol{s}_{\text {min }} \leq s(t) \leq \boldsymbol{s}_{\max }
$$

The power plant faces maximum and minimum water spill rate requirements, denoted by $q_{\min }, q_{\max }$

$$
q_{\min } \leq q(t) \leq q_{\max }
$$

In order to avoid of overtop and damaging the dam mostly during flood periods (spring season), spillways may discharge water. Thanks to spillways that provides the flexibility of operations due to differences in water flow rates. The reservoir storage volume at the end of the reference period is to be equal to storage volume at the beginning of such period.

$$
1 m \leq \mathrm{s}_{\text {initial }}, s_{\text {end }}
$$

It is also assumed that the power facility is facing maximum and minimum energy generation restrictions, the generated power has lower and upper bounds which can be written as:

$$
P_{\text {min }} \leq P(t) \leq P_{\max }
$$

Ecological constraints: Environmental flow requirements are considered. The environmental flow determined and recommended by the State Hydraulic Works General Directorate is at least $10 \%$ of the 10 -year average lead $[19,20]$.

$$
w_{\text {eco }}(t) \geq \% 10 . \zeta(t)
$$

Where;

$v(t)$ : reservoir level at time $t$;

$s_{\text {max }}:$ maximum reservoir level

$s_{\text {min }}$ : minimum reservoir level

$s_{\text {initial }}$ : initial reservoir level

$S_{\text {end }}$ : at the end of day reservoir level

$w(t):$ waterdischarge at time $t$, in $\mathrm{m}^{3} / \mathrm{s}$

$w_{l}(t)$ : lower bound of operating reservoir level at time $t$.

$w_{u}(t)$ : upper bound of operating reservoir level at time $t$.

$w_{\text {max }}:$ maximum water discharge at time $t$

$w_{\text {min }}$ : minimum water discharge at time $t$

$c(t)$ : electricity market price at time t per MWh in $€$

$\zeta(t)$ : naturel water inflow in river at time $t$

$F(t)$ : income at time $t$, in $€$

$w_{\text {eco }}(t)$ the water spillage for fish gate in hour $t$;

$\gamma$ : the spesific weight of water in $\mathrm{kN} / \mathrm{m}^{3}$

$H:$ the net head in meters

$n$ : the overall efficiency of the facility (\%)

It is worth mentioning that the investigation in this research report is for a single reservoir type hydropower plants. If water usage (ecological) restrictions were applied to the power generation capacity in a region or specific area, then the effect on the whole network need to be studied. A full study of water usage limitations on a hydro generation have to take into account the less efficiently running fossil fuel power plants for the increased cost potential in handling peak demands, or by adding fuel-fired units that operate with additional cost.

When constrained, hydropower working conditions maximize the income value by storing water when electricity demand (price) is low and when demand is high; discharge water through turbines. In most cases, two peak flow arrangement is expected with this path. First one is seasonal, which is a great amount

93 | P a g e

www.iiste.org 
of spring run-off are stored for release during summer when the use of energy increases. The second one is the daily pattern, which is water is stored overnight and then discharge the following day during daily peak demand. River structures managed for hydropower demonstrate one or both of these designs. The commitment of ecological limitations intrinsically reduces the value of a river as an energy generator. The limitations can affect daily flow rates or seasonal patterns to improve the natural environment of a river.

The target of the study is on water reservoir rate constraints, and test the cost as the lost income caused by to meet these limitations, which causes pollutant emissions by fossil fuel power plants. Please note that environmental restrictions do not determine the advantages of reducing pollution in the aquatic environment beyond the scope of the present article.

\section{Case Study}

The representative hydropower facility is used in experimental example which is ranked as a small size power house in Ardahan city, Turkey. The optimal operation of the power plant was modeled over a period of 48 hours. The first scenario for water usage constraints decreases the extent of energy generation shifting. However, at the end of the 17th and 33rd hour which is in the peak period, the power plant can generate more energy. In Figure 3 it is observed that environmental restrictions play essential role on income. As seen in results; the income is $11359 €$ for $90 \%$ of water usage restrictictions which is as stated in the law while the income is $12531 €$ without taking into account water usage limitations, and the income is $11712 €$ and $11947 €$ for $93 \%$ and $95 \%$ of water usage restrictictions respectively.
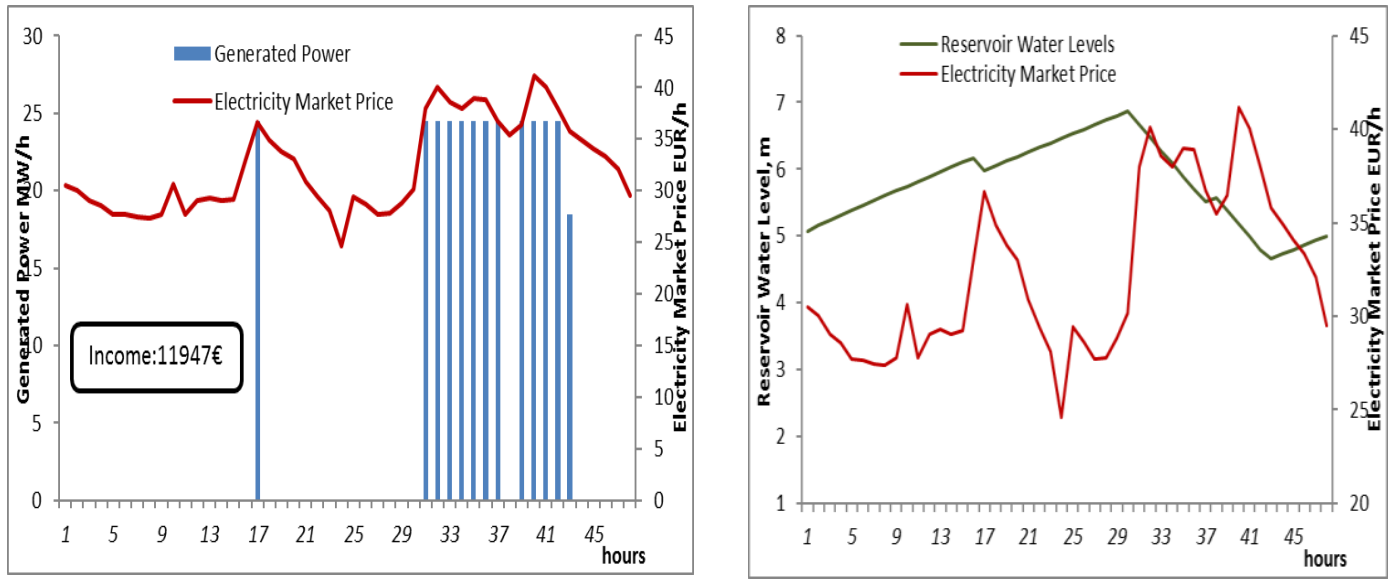

Figure 1. Schedule of the HPP with $95 \%$ of water usage restrictions
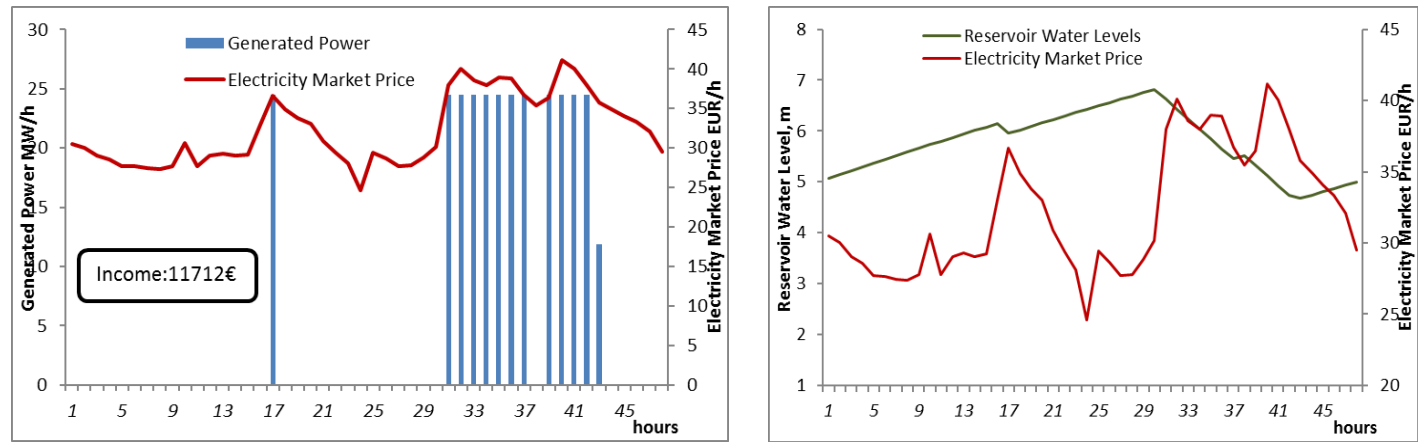

Figure 2. Schedule of the HPP with $93 \%$ of water usage restrictions 

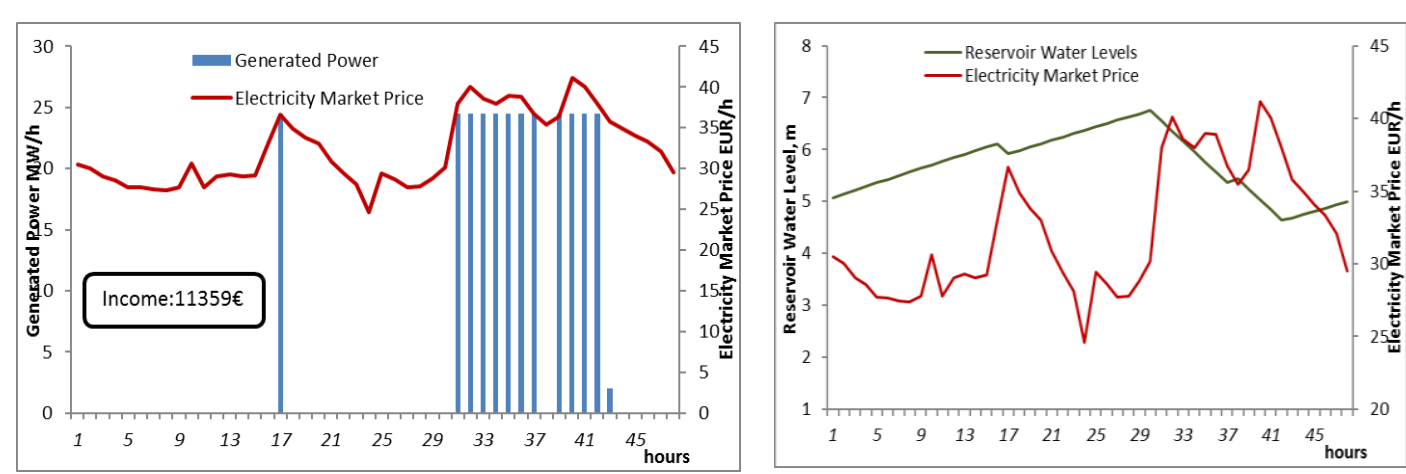

Figure 3. Schedule of the HPP with $90 \%$ of water usage restrictions
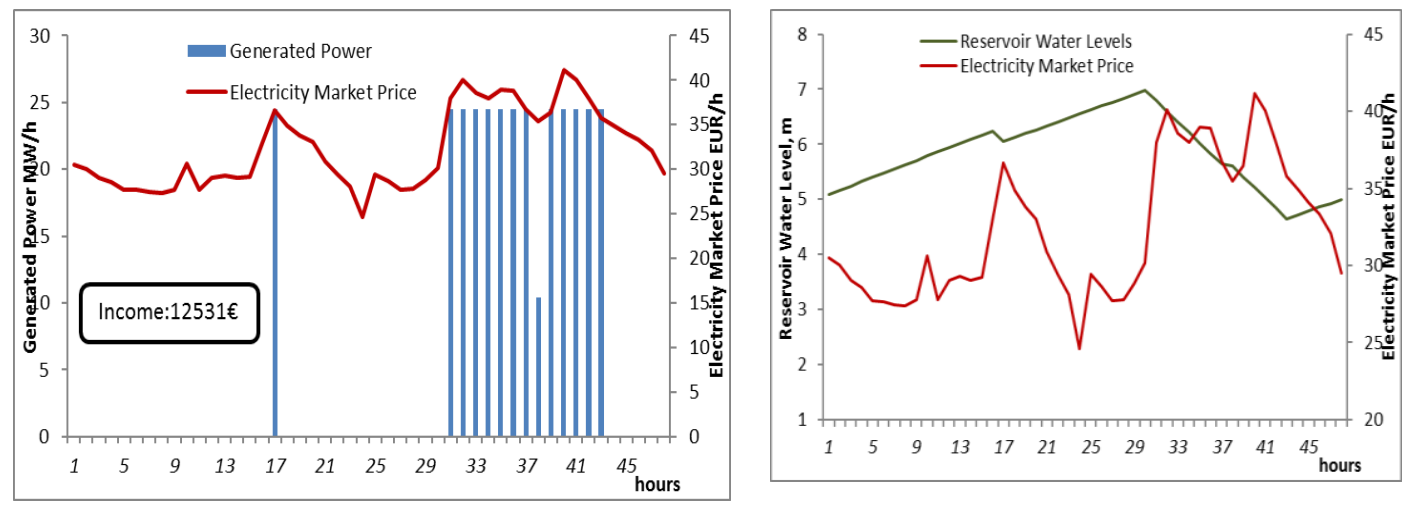

Figure 4. Schedule of the HPP without water usage restrictions

The Figure 5 shows which turbine is online at each hour market by

\begin{tabular}{|c|c|c|c|c|c|c|c|c|c|c|c|c|c|c|c|c|c|c|c|}
\hline Tim & & \begin{tabular}{|l|l|}
$5: 00$ & $6: 00$ \\
\end{tabular} & $7: 00$ & $8: 00$ & 9:00 & 10:00 & 11:00 & 12:00 & 13:00 & $14: 00$ & $15: 00$ & 16:00 & $17: 00$ & $18: 00$ & $19: 00$ & 20:00 & 21:00 & $22: 00$ & $23: 00 \quad 0: 00$ \\
\hline & $1 s t$ & & & & & & & & & & & & & & & & & & \\
\hline Turbine & 2nd & & & & & & & & & & & & & & & & & & \\
\hline INumioer & $3 r d$ & & & & & & & & & & & & & & & & & & \\
\hline
\end{tabular}

Figure 5. Online turbine chart in hours

In second scenario it is added reservoir maximum water level and reservoir minimum water level restrictions, which are set initially at maximum 8 meter and minimum 7, 7.1, 7.3, 7.5 meter respectively. As shown in Figure 6, the highest peak water discharge rate during the day with water level restrictions reaches a maximum of in the $30^{\text {th }}-42^{\text {nd }}$ hour. Detailed results are given in Figure $6,7,8,9$. As seen from Figure 6 while the permissible upstream level was $8 \mathrm{~m}$ and downstream level was $7 \mathrm{~m}$ the income was $27506 €$, when downstream level increased to $7.5 \mathrm{~m}$ the income was decreased to $27110 €$. 


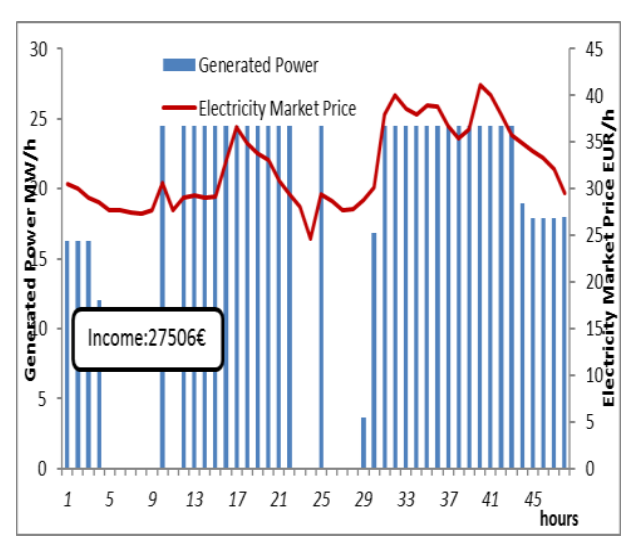

Figure 6. Permissible water level 8-7m

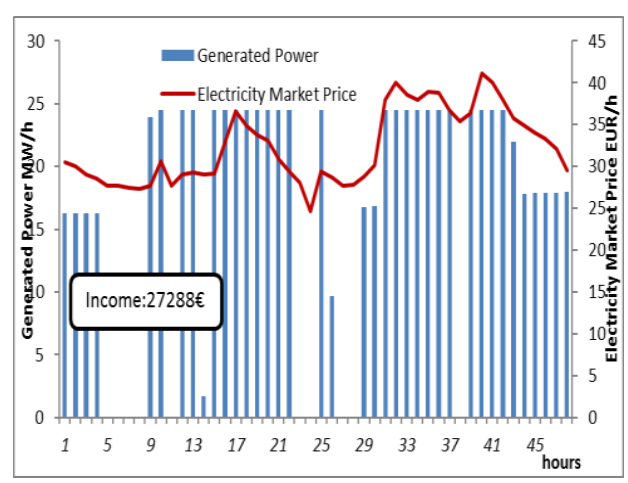

Figure 8. Permissible water level 8-7.3m

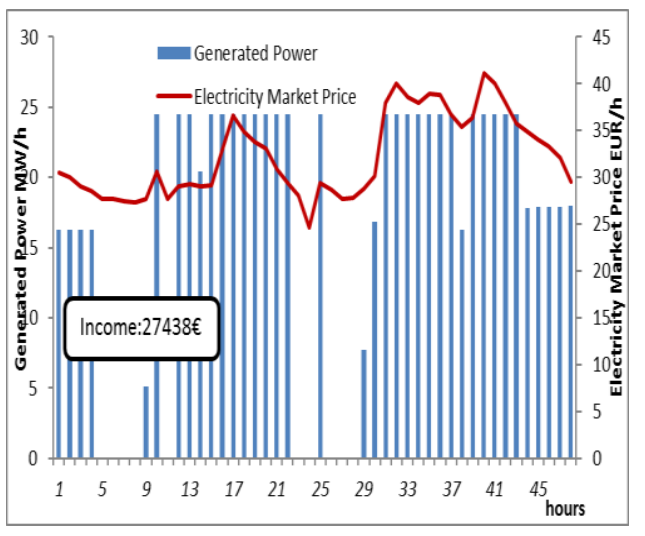

Figure 7. Permissible water level 8-7.1m

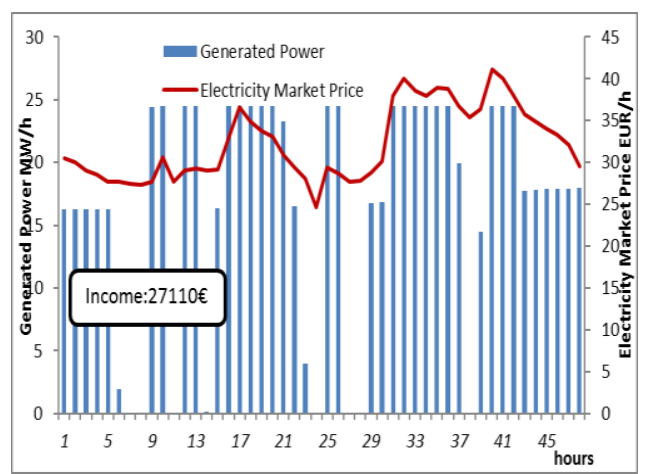

Figure 9. Permissible water level 8-7.5m

These results are consistent. Due to the lower limit of total water in the water reservoir, it is in the interests of the operator of the power plant to release the permissible water amount when the electricity price is the highest. Additionally, as a main contribution of this paper; to maximize the income of hydro facility, the powerhouse accumulates water during the off-peak period for the discharge of on-peak periods and sells electricity to its customers.

\section{Conclusion}

One of the benefits of hydropower is it responds quickly through water usage to changing demand conditions. In order to protect natural life; the possibility of negative consequences of the amount of water to be given to the river must be considered by regulators on aquatic ecosystems. As long as where water usage rate restrictions are being studied, the hydroelectric power plant operators need to recognize the costs they provide without losing profits.

It has been concluded that the environmental impact of hydropower plants/projects is significant and calls for critical study during its environmental administration process. Thus, the total cost of producing electricity should reflect environmental components in order to serve as an adequate basis for pricing units of production.

Admirably water usage rules would be determined through a careful study of all the possible influences. The main contributions of this paper are to understand these economic impacts and how the income influenced by ecological restrictions involved. One of the essential results of the paper is that ecological limitations should not be regulated in isolation, but instead of using a cost-benefit analysis that figures out the possible profit involved.

For future work; this article describes the major ecological constraints which should be considered more preciously at minor level. It would be better to include the environmental impact and the cost of uses traditional fuels of fluctuations in the intensity of use of other types of energy sources. 


\section{References}

[1] Hydropower Status Report, 2016, International Hydropower Association. Page:6.

[2] World Energy Council, World Energy Resources, 2016, Page:3.

[3] O Yuksek, M Kankal, M Komurcu, H Onsoy, The importance of hydropower plants in Turkey's energy planning, Basin Water Management, Page:720-732.

[4] Renewables, S. (2016). The Benefits of Pumped Storage Hydro to the UK. Report, DNV GL, London.

[5] Smokorowski, K. E., Metcalfe, R. A., Jones, N. E., Marty, J., Niu, S., \& Pyrce, R. S. (2009). Studying Ramping Rate Restrictions-Testing is under way to determine whether the regulation of ramping rates of hydroelectric turbines can provide ecological benefits while, at the same time, minimize production losses. Hydro Review, 28(5), 68.

[6] Elektrik Piyasasinda Uretim Faaliyetinde Bulunmak Uzere Su Kullanim Hakki Anlasmasi İmzalanmasina İliskin Usul ve Esaslar Hakkinda Yonetmelik 21 February 2015 Official Newspaper issue: 29274, Electricity Market Law issue:6446.

[7] Kentel, E., \& Alp, E. (2013). Hydropower in Turkey: economical, social and environmental aspects and legal challenges. Environmental science \& policy, 31, 34-43.

[8] Kotchen, M. J., Moore, M. R., Lupi, F., \& Rutherford, E. S. (2006). Environmental constraints on hydropower: an ex post benefit-cost analysis of dam relicensing in Michigan. Land Economics, 82(3), 384-403.

[9] Hasan Huseyin Coban, Optimization Techniques in Short and Long-Term Power Production at Small Hydropower Plants, PhD thesis, 2016.

[10] Hydropower Economics: An Overview, Finn R. Forsund

[11] Collier, U., House, P., \& Park, W. (2004, October). Hydropower and the environment: Towards better decision-making. In Global Freshwater Program, WWF International paper submitted to the UN Symposium on Hydropower and Sustainable Development. Beijing.

[12] Harpman, D. A. (1999). Assessing the short-run economic cost of environmental constraints on hydropower operations at Glen Canyon Dam. Land Economics, 390-401.

[13] Archsmith, J. (2017). Dam Spillovers: The direct and indirect costs from environmental constraints on hydroelectric generation. Available at SSRN 3046246.

[14] Niu, S., \& Insley, M. (2013). On the economics of ramping rate restrictions at hydro power plants: Balancing profitability and environmental costs. Energy Economics, 39, 39-52.

[15] Sauhats, A., Coban, H. H., Baltputnis, K., Broka, Z., Petrichenko, R., \& Varfolomejeva, R. (2016). Optimal investment and operational planning of a storage power plant. International Journal of Hydrogen Energy, 41(29), 12443-12453.

[16] Varfolomejeva, R., Sauhats, A., Sokolovs, N., Coban, H. (2017). The influence of small-scale power plant supporting schemes on the public trader and consumers. Energies, 10(6), 800. 
[17] Otuagoma, S. O., Ogujor, E. A., \& Kuale, P. A. (2016). Determination of Head for Small Hydropower Development: A Case Study of River Ethiope at Umutu. Nigerian Journal of Technology, 35(1), 190-195.

[18] Statistical data from Nordpool spot: www.nordpoolspot.com

[19] Islar, M. (2012). Privatised hydropower development in Turkey: a case of water grabbing? Water Alternatives, 5(2).

[20] Regulation On the Procedures and Principles Regarding Water Use Right Agreement On the Production Activity of the Electricity Market, February 21, 2015 Saturday, Official newspaper, Number: 29274, Article: 14 